\title{
Multi-detector Computed Tomography Angiography
}

National Cancer Institute

\section{Source}

National Cancer Institute. Multi-detector Computed Tomography Angiography. NCI

Thesaurus. Code C157338.

Angiography that uses multi-detector computed tomography. 